\title{
Energy passivation of a building. The ICSTM building case study
}

\author{
Otilia Nedelcu $^{1, *}$, Ioan Corneliu Salisteanu ${ }^{1}$, Traian Ivanovici $^{1}$, and Valentin Dogaru ${ }^{1}$ \\ ${ }^{1}$ Valahia University of Targoviste, Department of Electronics, Telecommunication and Energy \\ Engineering, Aleea Sinaia no.13, Targoviste, 130004, Romania
}

\begin{abstract}
The renewable energy sources are becoming more and more current in the energy supply of buildings, from residential buildings to institutional buildings. The renewable energy sources have proved to be a solution and an important element of the Romanian Energy System. We are starting from the idea of using the renewable sources to passivize a building, and we are relying on existing facilities in the Multidisciplinary Scientific and Technological Research Institute (ICSTM) from Valahia University of Targoviste (UVT) to produce the energy from its own sources. We are also considering the consumption data from previous year as well as the electric link to external power grid. This paper aims to propose new renewable energy units so that ICSTM become energetical independent. Currently, the ICSTM building consumes an amount of energy produced from renewable sources about three times less than that consumed from the external network. In order to determine the number of equipment, specifically CPV (concentrating photovoltaic) panels placed on trackers, it is desirable to create a $40 \%$ reserve above the installed power, taking in account the possible future development of the research laboratories.
\end{abstract}

\section{Introduction}

An energy-efficient construction is no more than a construction concept that can be reached and applied by anyone. [1]

Multidisciplinary Scientific and Technological Research Institute is part of the UVT, being built on an area with a ground footprint of $2240 \mathrm{~m}^{2}$ and a total built area of $7250 \mathrm{~m}^{2}$. The internal part of the building is formed by 35 laboratory spaces, 5 technological laboratories, 6 functional annexes, 7 administrative spaces and 4 dissemination spaces, with installations and equipment used for different activities of research. [2]

Multidisciplinary Scientific and Technological Research Institute is equipped with more sources which produce renewable energy: photovoltaic platform, wind platform, thermosolar platform.

All those sources cover only one part from necessary consumption for ICSTM, the other part is consumed from the National Energy System (SEN) network.

\footnotetext{
* Corresponding author: otilia.nedelcu@,valahia.ro
} 


\section{The current state of the ICSTM supply with energy from renewable sources}

The current ICSTM equipment consists of:

-The photovoltaic experimental platform which has an active surface of more $250 \mathrm{~m}^{2}$, and the installed approximate power of $79,65 \mathrm{kWp}$;

-The wind experimental platform which has the installed approximate power of $25 \mathrm{kWp}$;

-The thermo-solar experimental platform which has the active surface of more $250 \mathrm{~m}^{2}$, with an approximate capacity of 10000 litters.

\subsection{The photovoltaic experimental platform}

This platform is composed of many installations with different installed powers:

$>$ OnGrid installation, which is located on the institute's terrace, it has PV panels with the orientation towards south and the inclination $45^{\circ}$. The installed power is $33.15 \mathrm{kWp}$. It is consisting of three type of panels: monocrystalline silicon panels, polycrystalline silicon panels and amorphous silicon panels. It is equipped with 6 inverters of SMA 5000TL$21 \mathrm{~kW}$ type. [2]

$>$ OffGrid installation located on the ICSTM terrace, it has PV panels with the orientation towards south and the inclination $30^{\circ}$. It has the installed power of $42.5 \mathrm{kWp}$ and it is consisting of two types of PV panels, two types of invertors and 100 batteries.

$>\quad$ The Off Grig installation of parasolar type.

The ICSTM building is separated in three building bodies and the panels repartization had been made in the following way: the system in front of ICSTM consists of 120 photovoltaic panels of semi-transparent Altius AFP type.

PV of parasolar type consists of polycrystalline silicon panels with the $250 \mathrm{~W}$ nominal power.

- $\quad$ The OffGrid installation of curtain type. It consists of 51 Q.Cells Q.Pro-G3 BLK photovoltaic panels, polycrystalline silicon panels, 7 inverters of Victron Multiplus $5 \mathrm{~kW}, 2$ inverters of Victron Multiplus $3 \mathrm{~kW}$ and 100 VRLA Gel Deep Cycle 220Ah and Victron VRLA Deep Cycle 220Ah batteries.

- $\quad$ Fixed Tracker with $4 \mathrm{kWp}$ power

The Tracker has two axes and the $25 \mathrm{~m}^{2}$ surface. It consists of 15 Q.Cells Q.Pro-G3 BLK photovoltaic panels and 2 SMA SunnyBoy $2 \mathrm{~kW}$ inverters. The photovoltaic panels on the tracker are from polycrystalline silicon.

\subsection{The wind experimental platform}

The wind experimental platform has the wind installations with turbines which have vertical axis or horizontal axis: the OnGrid installation; the MagLev installation; the SmallWind installation.

$>20 \mathrm{kWp}$ OnGrig installation on the ground has: one Aeolos HAWT wind turbine with $10 \mathrm{~kW}$ power and horizontal axis, $24 \mathrm{~m}$ monopole; the Aeolos VAWT wind turbine with 10 $\mathrm{kW}$ and vertical axis, $260 \mathrm{rpm}, 18 \mathrm{~m}$ monopole; two ABB Wind inverters $15 \mathrm{~kW}$.

$>$ MagLev installation. It is a wind turbine which function on the principle of magnetic levitation [3], it has vertical axis and is located on ICSTM terrace with $3 \mathrm{kWp}$ power.

$>2 \mathrm{kWp}$ SmallWind installation has: one Aeolos HAWT wind turbine with $1 \mathrm{~kW}$ power, horizontal; one Aeolos HAWT wind turbine with $1 \mathrm{~kW}$ power, vertical. 


\subsection{The thermo-solar experimental platform}

The thermo-solar experimental platform from ICSTM includes: the thermo-solar installation for heat input; the thermo-solar installation for domestic hot water.

$>26 \mathrm{kWp}$ Thermo-solar installation for heat input includes: 12 Westech SPS58/1800A-20 EHPT thermo-solar panels with vacuum tube; 5 Alfa-Bit Beta 58/1800-12 thermo-solar panels; 10 Tesy SP 07250 ASL flat-plate thermo-solar panels; Taconova Tacosol Circ ZR High efficiency pumping stations; Ferroli Ecounit 1000-2WB heat exchanger and storage boilers.

> thermo-solar installation for domestic hot water by 600 liters which includes: two SunSystem boilers of 300 litres -a thermosiphon system with flat catheters.

\section{The own produced energy and total consumption of energy from ICSTM}

Calculation were made for one calendar year considering the energy consumed from the produced energy by ICSTM's own equipment from and the energy consumed from national network and the cost for that moment.

Total energy produced by the photovoltaic platform in the studied period is 112417.22 $\mathrm{kWh}$, it shown in the figure 1 , the total produced energy by the wind platform is 21600.58 $\mathrm{kWh}$, it shown in the figure 2 , and the total produced energy by the thermo-solar platform is $21252.20 \mathrm{kWh}$.

Energy consumption in the same period from SEN was: the consumption of electrical energy $239908.4 \mathrm{kWh}$; the consumption of natural gas $259008.32 \mathrm{kWh}$, so a total consumption $498916.72 \mathrm{kWh}$ shown in the figure 3, this value represents an annual daily average of approximatively $59.95 \mathrm{kWh}$. The value payed to supplier was 35470.60 EURO.

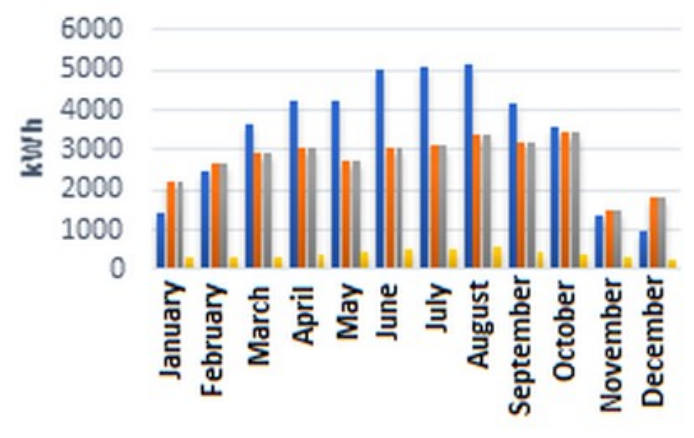

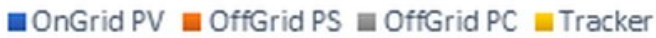

Fig. 1. The total produced energy by the photovoltaic platform 


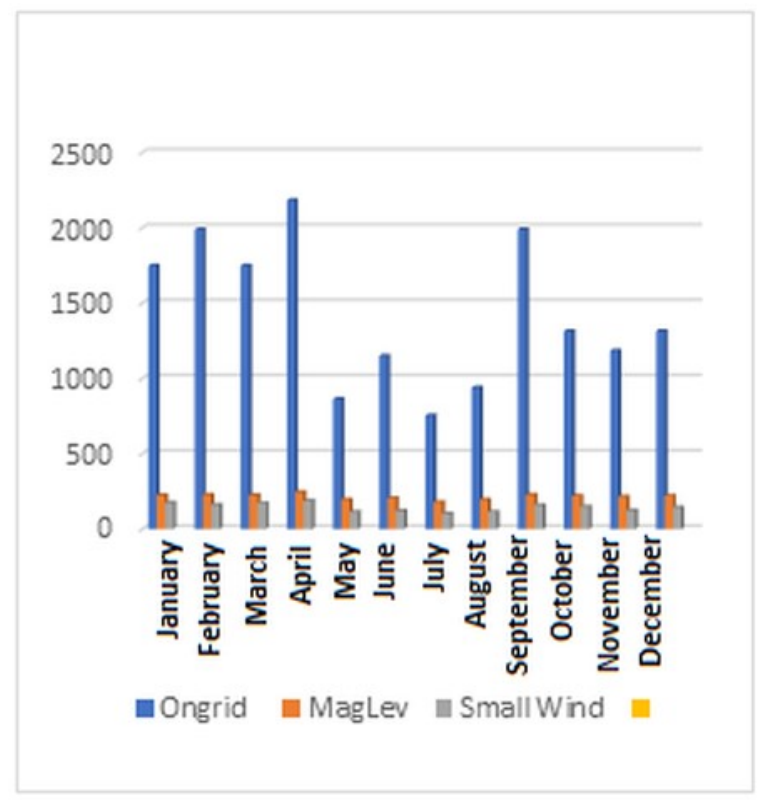

Fig. 2. The total produced energy by the wind platform

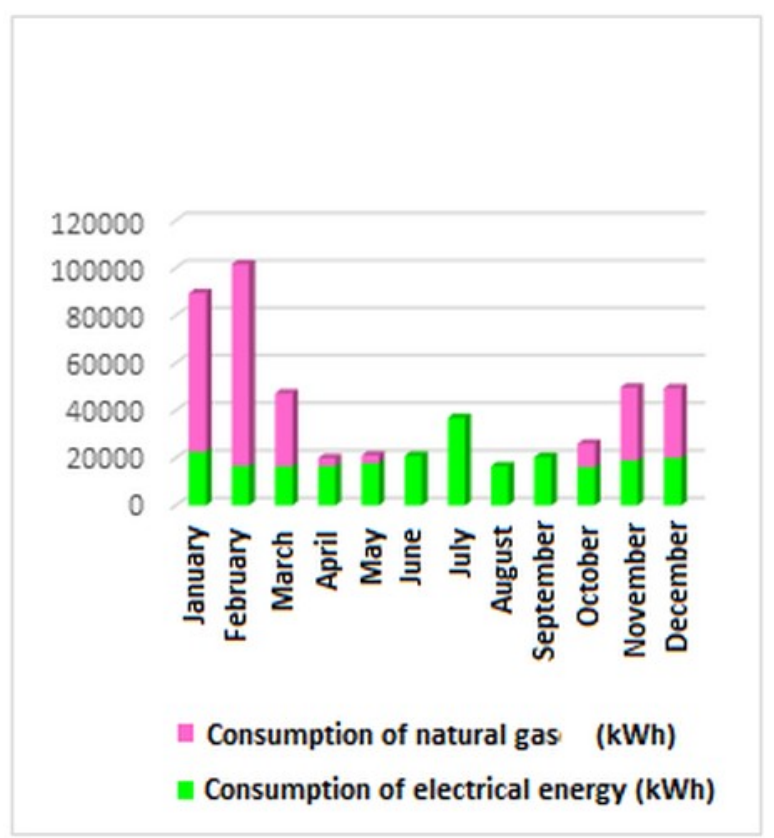

Fig. 3. The total consumption of energy from SEN

We find that the absorption of energy from the national network is about three times higher than the production of the developed energy with the currently own equipment as shown in figure 4. 


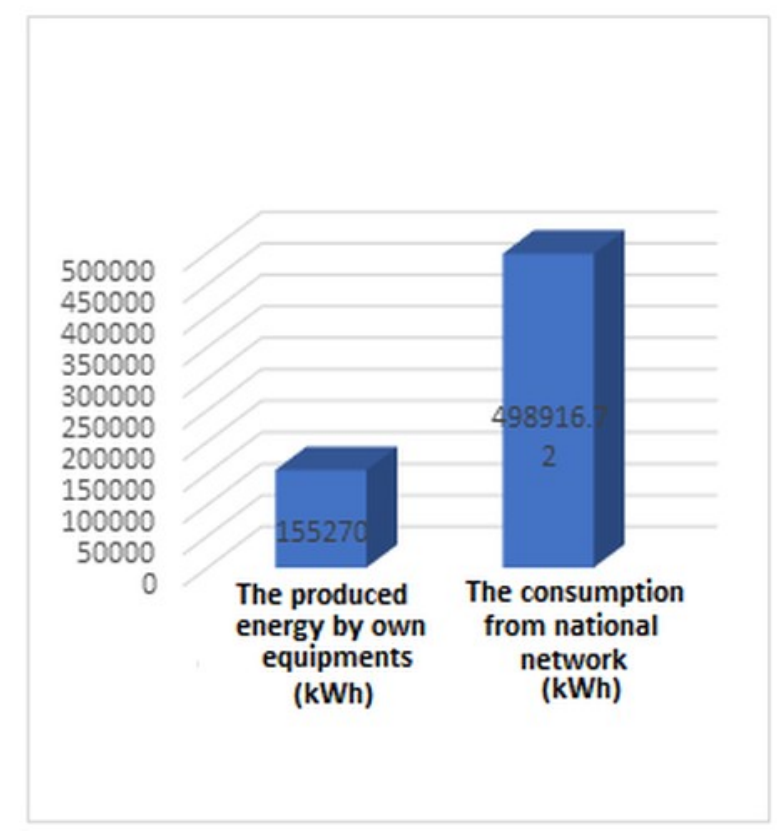

Fig. 4. The total energy (from national network and produced with own equipment)

\section{Proposal for the ICSTM building power supply only with energy from own renewable sources}

The purpose is to fully feed the ICSTM building whit renewable energy produced from own sources, because the amount of bills paid to the energy provider rises to very high values.

To cover all the energy consumption that ICSTM currently has but taking into account the possible development of ICSTM laboratories or the failure of current sources of renewable energy we need to consider a $40 \%$ surplus. This means that the necessary energy from renewable sources will increase to approximatively $689483.408 \mathrm{kWh}$ a year. Thus, the annual daily average needed will be around $80 \mathrm{kWh}$.

Solution we propose to achieve the autonomy of ICSTM building is: installing ten systems of concentrating photovoltaic panels (CPV) Tracker type with two axes of 12.00 kWp.

Trackers will be located near ICSTM building, figure 5, on same line whit the existing tracker on the right of the alley and other six on the left of the alley, between the alley and the Greek Amphitheatre, parallel whit the ICSTM building. 


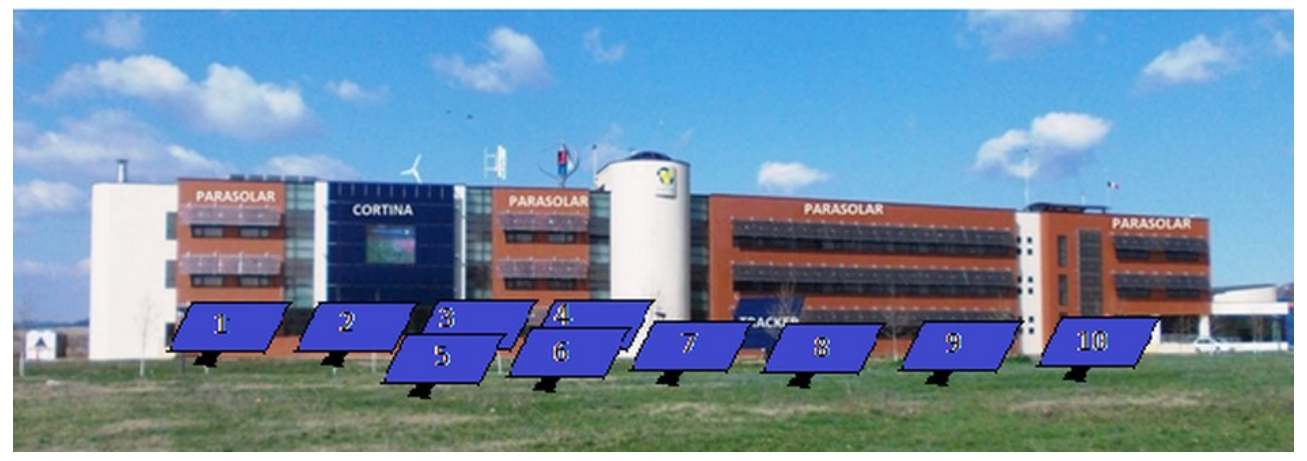

Fig 5. The location of the trackers

\subsection{The equipment chosen}

$>$ Concentrating photovoltaic panels (CPV) were chosen because these have the efficiency of $27.2 \%$ against the usual panels which have efficiency around $15 \%$. These panels behave well in small but unshaded spaces in tracker systems. [4]

Panels chosen are Concentrix Solar $75 \mathrm{Wp} \mathrm{CX-75} \mathrm{CPV} \mathrm{Multi-junction,} \mathrm{nominal}$ capacity $75 \mathrm{Wp}$, voltage MPP $135 \mathrm{~V}$, current MPP $0.55 \mathrm{~A}$, short circuit current $0.64 \mathrm{~A}$, output circuit voltage $150 \mathrm{~V}$, maximum voltage $1000 \mathrm{~V}$, length $828 \mathrm{~mm}$, width $428 \mathrm{~mm}$, weight $9.5 \mathrm{~kg}$.

$>$ Tracker - because the concentrating photovoltaic panels (CPV) have smaller sizes than classic ones, and the tracker offers a more space than the existing one, approximatively $70.6 \mathrm{~m}^{2}$, we will used 198 panels a single tracker. The nominal power is $8000-12000 \mathrm{Wp}$, the elevation angle is from $10^{\circ}$ to $90^{\circ}$ and the rotation angle Est-West of maximum $300^{\circ}$.

$>$ Inverter -5 inverters SolarMax 20C type will be used, with recommended PV power $24000 \mathrm{~W}$, Max. DC input voltage $900 \mathrm{~V}$, Max. DC input current $48 \mathrm{~A}, \mathrm{AC}$ nominal power $20000 \mathrm{~W}$, maximum AC output power $20000 \mathrm{~W}$, weight $275 \mathrm{~kg}$.

$>$ Batteries - To ensure the storage of produced energy by the ten trackers (1980 panels) is takes 4 modules of 40 batteries are needed which together give:

$$
40 \text { batteries } x 480 \mathrm{~V} \times 260 \mathrm{~A}=124.8 \mathrm{~kW}
$$

Batteries will be Battery Rolls Solar 4000 - S260 type with the nominal capacity of $200 \mathrm{Ah} / \mathrm{C} 20-266 \mathrm{Ah} / \mathrm{C} 100$, voltage $12 \mathrm{~V}$. [5]

$>$ Regulator - the type chosen is REGULATOR VICTRON ENERGY BLUESOLAR MPPT $150 / 60$ - TR with the characteristics: auto-selector system voltage/battery $12 / 24 / 36 / 48 \mathrm{~V}$, power of photovoltaic panels $12 \mathrm{~V}-860 \mathrm{~W} / 24 \mathrm{~V}-1720 \mathrm{~W} / 48 \mathrm{~V}-3440 \mathrm{~W}$, the maximum voltage for photovoltaic panels $150 \mathrm{~V}$ when the temperatures is low / maximum 145 to start and normal operating, maximum charge current $60 \mathrm{~A}$, maximum efficiency $98 \%$ and the operating temperature $-30 /+60^{\circ} \mathrm{C}$.

$>\quad$ PV electric cable $-500 \mathrm{~m}$

On a tracker with the chosen dimension are necessary $198 \mathrm{CPV}$ panels and we obtain for each formed system $10 \mathrm{kWh}$. Given that we need 10 such systems, the total cost for the panels is 135229.79 EURO. 
Table 1. The total costs on the investment.

\begin{tabular}{|c|c|c|}
\hline Equipment & $\begin{array}{c}\text { Number of } \\
\text { equipment }\end{array}$ & Price (EURO) \\
\hline Concentrix Solar 75Wp CX-75 CPV Multi-junction & 1980 & 135229.79 \\
\hline Invertor - SolarMax - SolarMax 20C & 5 & 7420.22 \\
\hline Battery Rolls Solar 4000 - S260 & $\begin{array}{c}160(4 \\
\text { modules) }\end{array}$ & 48935.90 \\
\hline Tracker & 10 & 122340.50 \\
\hline PV electric cable & $500 \mathrm{~m}$ & 590.00 \\
\hline REGULATOR VICTRON ENERGY BLUESOLAR \\
MPPT 150/60 - TR & 10 & 5000 \\
\hline Set cables/box connections/fuses/connectors & & 1900.00 \\
\hline The workmanship & & $\mathbf{3 3 8 4 6 9 . 9 0}$ EURO \\
\hline The total cost & & \\
\hline
\end{tabular}

\subsection{The amortization of the costs}

The total cost of purchasing the sources used to obtain ICSTM energy passivation, is 338470 EURO. Regarding the values of the bills in one year, which ICSTM payed 35470.563 EURO, we can approximate the amortization time for the investment costs.

Table 2. The amortization of the investment costs.

\begin{tabular}{|c|c|c|c|}
\hline \multicolumn{5}{|c|}{ Initial Investment - 338470 EURO } \\
\hline \multicolumn{5}{|c|}{ The produced energy on year - 698.483 MWh } \\
\hline The year & $\begin{array}{c}\text { The produced } \\
\text { energy } \\
\text { MWh }\end{array}$ & $\begin{array}{c}\text { The amortization of the } \\
\text { investment } \\
\text { (RON)/(EURO) }\end{array}$ & $\begin{array}{c}\text { The remaining } \\
\text { amortized value } \\
\text { (RON)/(EURO) }\end{array}$ \\
\hline 1 & 698.483 & 35470.563 & 302999.2 \\
\hline 2 & 691.498 & 35470.563 & 267528.7 \\
\hline 3 & 684.583 & 35470.563 & 232058.2 \\
\hline 4 & 677.737 & 35470.563 & 196587.6 \\
\hline 5 & 670.959 & 35470.563 & 161177 \\
\hline 6 & 664.249 & 35470.563 & 90175.9 \\
\hline 7 & 657.606 & 35470.563 & 54705.3 \\
\hline 8 & 651.030 & 35470.563 & 19234.75 \\
\hline 9 & 644.520 & 35470.563 & \\
\hline
\end{tabular}




\begin{tabular}{|l|l|l|l|}
\hline 10 & 638.075 & 19234.75 & 0 \\
\hline 11 & 631.694 & & 0 \\
\hline 12 & 625.377 & & 0 \\
\hline 13 & 619.123 & & 0 \\
\hline 14 & 612.932 & & 0 \\
\hline 15 & 606.803 & & 0 \\
\hline 16 & 600.735 & & 0 \\
\hline 17 & 594.727 & & 0 \\
\hline 18 & 588.780 & & 0 \\
\hline 19 & 582.892 & & 0 \\
\hline 20 & 577.063 & & 0 \\
\hline 21 & 551.293 & & 0 \\
\hline 22 & 565.580 & & 0 \\
\hline 23 & 559.924 & & 0 \\
\hline 24 & & & 0 \\
\hline Total & & & 0 \\
\hline
\end{tabular}

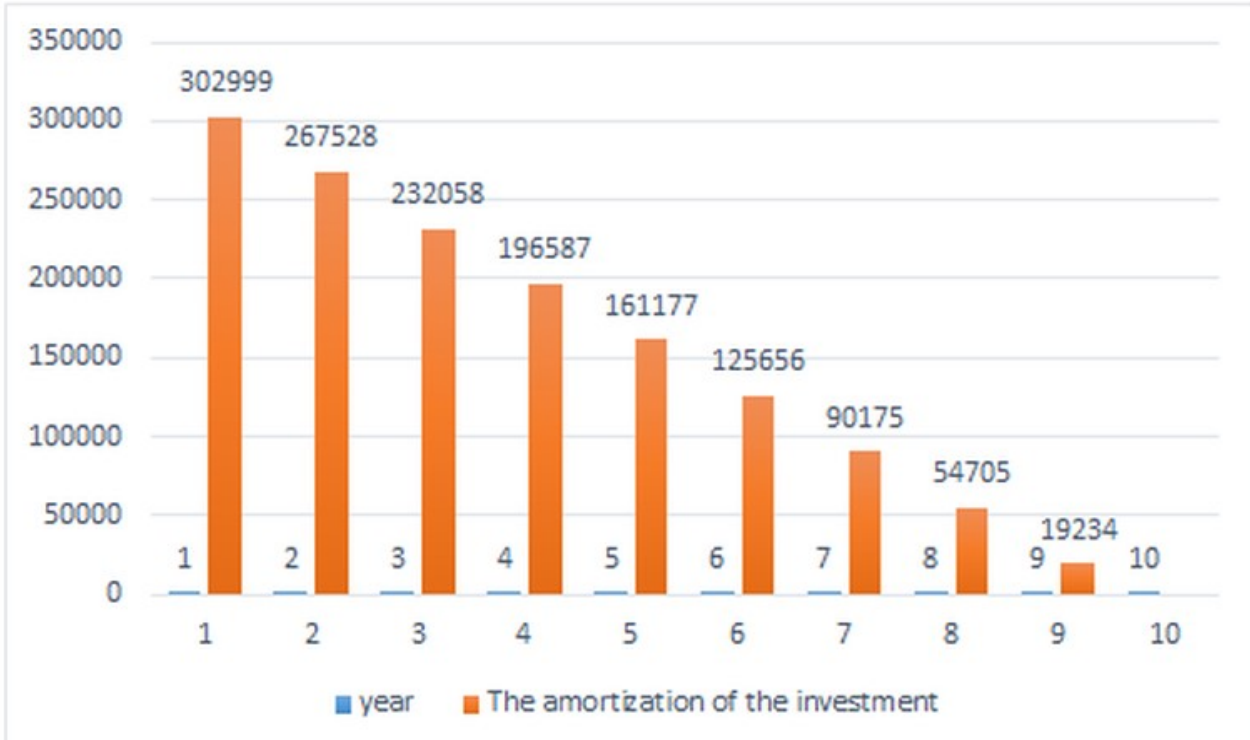


Fig. 6. The amortization of the investment

The amortization of the investment is made in 9 years and 7 months, and the lifetime of the equipment in 25 years, table 2, figure 6.

\section{Conclusions}

The ICSTM building is now partially powered from renewable sources and partially from national network (SEN) of energy. The quantity of energy produced from renewable sources is about three times less than the energy consumed from the national network.

The study drawn for the ICSTM building to became autonomous in terms of energy consumption shows that this is possible if we add to the current renewable sources, some others renewable sources.

The best solution resulted after several atempts, is the use of $1980 \mathrm{CPV}$ panels mounted on 10 trackers with 10 charge regulators for 4 banks which contain each 40 batteries and 5 inverters $-24 \mathrm{~kW}$ toghether with necessary materials for instalation.

When we determined the number of equipment, a $40 \%$ reserve over the required power to install for the future development of the research laboratories was considered.

By comparing the cost of the investment with the value of the energy bills, it was found that the investment is depreciated within 9 years and 7 months, the lifetime of the equipment being 25 years.

\section{References}

1. I.R. Rancov, Cercetari privind cresterea randamentului instalatiilor electrice fotovoltaice, Editura Politehnica, Timisoara, (2014)

2. http://916.icstm.ro/content/rezultate-obtinute

3. B.K. Balankutty, A. Raju, H. A. Mammen. A.K. Abraham, Design and Analysis of Maglev Vertical Axis Wind Turbine, International Journal of Emerging Technology and Advanced Engineering Website: www.ijetae.com (ISSN 2250-2459, ISO 9001:2008 Certified Journal, Volume 4, Issue 4, April (2014)

4. https://www.secondsol.com/de/anzeige/13085/photovoltaikmodule/konzentriertephotovoltaik-cpv/soitec/concentrix-solar-75wp-cx-75-cpv-multi-junction

5. http://www.e-solare.com/produs/battery-rolls-solar-4000-t12-250 